\title{
Autologous Transfusion - from Euphoria to Reason: Clinical Practice Based on Scientific Knowledge
}

'Your own blood is the safest blood' - this is the statement of the American Association of Blood Banks (AABB) on its official 'Autologous Blood Poster' [1]. It is made for lays in order to promote preoperative autologous blood donation (PABD) and to demonstrate its potential advantages. Autologous transfusion has become an established component of the patient's blood supply. However, after having done the emotional difficult step 'from euphoria to reason' the next logical step of autologous blood management should be done, namely 'from reason to quality management and quality assurance'. In Germany, quality management concerning both autologous and allogeneic blood transfusion has been given by the German Transfusion Act (Transfusionsgesetz - TFG) from 1998 [2]. Concerning autologous transfusion, quality management was of minor importance to the clinician so far, and stood far behind routine autologous clinical practice. Due to the continuous increase in safety of allogeneic blood, the total risk of autologous blood donation/intraoperative blood salvage plus retransfusion of the appropriate autologous blood products should be smaller than with allogeneic blood transfusion [3]. This, however, means that autologous blood conservation measures have to achieve given quality standards. Therefore, the 3rd International CAT Symposium that was held on January 16-17, 2004 in Nottwil, Switzerland, intensively dealt with quality and safety perspectives of autologous transfusion.

Under legal perspectives, PABD which describes both preoperative blood collection and its hemoseparation into autologous packed red blood cells (RBCs) and fresh frozen plasma represents a pharmaceutical procedure comparable to manufacturing of a drug. It has to be made known to the appropriate official local authority and needs its approval for production [4]. German guidelines [5] by the Bundesärztekammer and the Paul-Ehrlich-Institut describe both the appropriate minimal prerequisites with respect to PABD and the corresponding autologous products and the transfusion-specific ed- ucation for physicians in charge of an autologous blood bank and autologous manufacturing. These guidelines primarily aim at quality measures concerning the safety of the blood products. However, concerning the patient's benefit from autologous transfusion, it is important to consider efficacy of autologous transfusion measures, too, i.e., increase in total RBC mass is an additional and clinical important quality parameter. Since PABD per se represents nothing else but the transfer of patient's RBCs from his/her body into a plastic bag, availability of a given number of autologous units does not represent an appropriate or even identical increase in total RBC mass. Only, if the decisive determinants of the efficacy of PABD are considered, PABD will result in an additional increase in RBC mass, and may be associated with a decreased need for allogeneic blood.

Under legal perspectives, and in contrast to PABD, neither perioperative blood salvage (PBS) and its mechanical processing by sophisticated technology nor autologous direct retransfusion of salvaged but unwashed wound blood (ADR) nor acute normovolemic hemodilution (ANH) do represent manufacturing of a drug. Due to their timely close relation to the surgical intervention, these measures are considered an integrated part of a patient's medical treatment, and, therefore, do not need the approval by the local health authority [4]. However, with respect to these autologous measures, quality perspectives referring to product safety and efficacy have to be considered and established, too [6]. In addition, concerning PBS in patients undergoing tumor surgery, medical and legal perspectives are to be discussed with respect to irradiation of the processed blood product before its retransfusion. Intense discussion on this topic at this symposium resulted in partial amendment of the appropriate part of the TFG to legally enable application of PBS, irradiation of the processed blood product, and its retransfusion to this special group of patients [7].

\begin{tabular}{|c|c|}
\hline KARGER & (C) 2004 S. Karger GmbH, Freiburg \\
\hline $\begin{array}{l}\text { Fax +497614520714 } \\
\text { E-mail Information@Karger.de } \\
\text { www.karger.com }\end{array}$ & $\begin{array}{l}\text { Accessible online at: } \\
\text { www.karger.com/tmh }\end{array}$ \\
\hline
\end{tabular}


ADR is mainly applied in cardiac and orthopedic surgery patients. However, this measure is discussed controversially with respect to its efficacy, effectiveness, cost-effectiveness, and potential risks of adverse events. It seems impossible to establish given quality standards for this measure comparable to those of PABD, PBS, and allogeneic RBC units regarding hematocrit, plasma hemoglobin or unwanted by-products being released either from platelets and white blood cells, or resulting from blood coagulation/fibrinolysis. Measures to improve the quality of this procedure and the respective blood product may be of scientific relevance to the researcher interested; however, a reasonable relation between efficacy, effectiveness, cost-effectiveness and clinical benefit to the patient is to be questioned.

The discussion on the effectiveness of $\mathrm{ANH}$ as a blood/RBC conservation measure is as old as this measure is clinically applied, i.e. older than 20 years. However, this discussion does not consider the so-called dilution coagulopathy that represents both a quantitative problem of volume substitution applied and a qualitative problem of the type of volume substitute administered. The lower the 'transfusion trigger' accepted, the more important becomes the topic of dilution coagulopathy. With respect to blood coagulation neither cristalloids nor colloids, neither HES nor gelatine solution are 'inert'.

Another very often neglected perspective is application of autologous transfusion measures in children. Although these techniques might be limited to special centers, both anesthesiologists and clinically interested transfusion specialists should be aware of the basics of this special topic.

Artificial oxygen carriers of different chemical nature are under discussion and undergo clinical trials for years. Despite broad clinical interest and expectations, they are still not approved by the governmental authorities and thus are not available for routine clinical usage, at least in Western Europe. While this makes to critically question whether or not artificial oxygen carriers can fulfil what they are promising and we are expecting from them, another group of hemoglobin-based oxygen carriers, the so-called hemoglobin polymers, has come into focus; however, their investigation is in its very early experimental beginnings, and they have still a long way to go until tested in clinical trials.

An 'autologous symposium' without a fundamental discussion on the rational procedure and individual clinical management and acceptance of the 'transfusion trigger' could be consid- ered 'incomplete' - especially against the background of clinical studies dealing with tolerance of 'low' anemic hemoglobin levels by healthy volunteers, various groups of patients, and the clinical experience gathered from acceptance of dilution anemia during the last decade. Last but not least, this topic like the preceding ones - also stands for the basic idea of this symposium - 'clinical practice based on scientific knowledge'. By the agreement of the editors and publishers of journals mentioned below, it is possible to publish the lectures presented on this international/interdisciplinary symposium both in German in Anästhesiologie, Intensivmedizin, Notfallmedizin, Schmerztherapie (Thieme, Stuttgart) and in English in TRANSfusion Medicine and Hemotherapy (Karger, Freiburg i.Br.). The topic of autologous transfusion covers the interest of both anesthesiologists and transfusion specialists. Therefore, this kind of publication in two different languages and journals representing two different medical specialties was chosen by the guest-editors, in order to enable the presentation of the papers to the broad public of the two different clinical specialties interested and concerned. As the papers appear in two different languages, they are not considered a socalled 'double-publication' on the corresponding topic. The organizers of this symposium / guest-editors are very grateful both to the editors of these scientific journals for the opportunity to present the papers of this meeting and to the authors for their highly appreciated contributions.

G. Singbartl, Soltau, W. Schleinzer, Nottwil

\section{References}

1 Autologous Blood Poster: Bethesda, American Association of Blood Banks, 2003. E-mailsales@aabb.org.

2 Gesetz zur Regelung des Transfusionswesens (Transfusionsgesetz) vom 1. Juli 1998. Bundesgesetzblatt I, 1998, p 1752,

3 Karger R, Weippert-Kretschmer M, Kretschmer V: Preoperative autologous and plasma donation and retransfusion; in Kretschmer V, Blauhut B (eds): Blood, Blood Products, Blood Saving Techniques. Bailliere's Clin Anaesthesiol. London, Bailliere Tindall, 1997, vol 11, pp 319-333.

4 Deutsch E, Bender AW, Eckstein R, Zimmermann R: Transfusionsrecht. Stuttgart, Wissenschaftliche Verlagsgesellschaft, 2001.

5 Wissenschaftlicher Beirat der Bundesärztekammer und Paul-Ehrlich-Institut: Richtlinien zur Gewinnung von Blut und Blutbestandteilen und zur Anwendung von Blutprodukten (Hämotherapie). Köln, Deutscher Ärzte-Verlag, 2000.

6 Hansen E, Dietrich G, Kasper SM, Leidinger W, Singbartl G, Wollinsky KH: Vorschläge zum internen Qualitätsmanagement bei der Retransfusion von intraoder postoperativ gewonnenem Wund-/Drainageblut. Anästhesiol Intensivmed 2002;43:81-84. 